\title{
Vegetation NDVI Linked to Temperature and Precipitation in the Upper Catchments of Yellow River
}

\author{
Fanghua Hao $\cdot$ Xuan Zhang • Wei Ouyang • \\ Andrew K. Skidmore • A. G. Toxopeus
}

Received: 17 September 2008 / Accepted: 25 October 2011 /Published online: 19 November 2011

(C) The Author(s) 2011. This article is published with open access at Springerlink.com

\begin{abstract}
Vegetation in the upper catchment of Yellow River is critical for the ecological stability of the whole watershed. The dominant vegetation cover types in this region are grassland and forest, which can strongly influence the eco-environmental status of the whole watershed. The normalized difference vegetation index (NDVI) for grassland and forest has been calculated and its daily correlation models were deduced by Moderate Resolution Imaging Spectroradiometer products on 12 dates in 2000, 2003, and 2006. The responses of the NDVI values with the inter-annual grassland and forest to three climatic indices (i.e., yearly precipitation and highest and lowest temperature) were analyzed showing that, except for the lowest temperature, the yearly precipitation and highest temperature had close correlations with the NDVI values of the two vegetation communities. The value of correlation coefficients ranged from 0.815 to $0.951(p<0.01)$. Furthermore, the interactions of NDVI values of vegetation with the climatic indicators at monthly interval were analyzed. The NDVI of vegetation and three climatic indices had strong positive correlations (larger than $0.733, p<0.01$ ). The monthly correlations also provided the threshold values for the three climatic indictors, to be used for simulating vegetation growth grassland under different climate features, which is essential for the assessment of the vegetation growth and for regional environmental management.
\end{abstract}

F. Hao $\cdot$ X. Zhang $\cdot$ W. Ouyang $(\bowtie)$

School of Environment, State Key Laboratory

of Water Environment Simulation, Beijing Normal University,

Beijing 100875, China

e-mail: wei@itc.nl

A. K. Skidmore $\cdot$ A. G. Toxopeus

Faculty of Geo-Information Science and Earth Observation (ITC),

University of Twente,

Hengelosestraat 99, P.O. Box 6, Enschede 7500 AA,

The Netherlands
Keywords Vegetation dynamics · Correlation analysis . MODIS · Climatic feature · Yellow River

\section{Introduction}

The Yellow River is the second longest river in China and dominates the ecological stability in north China. The ecoenvironmental quality, especially the vegetation coverage status in the upper catchment, is critical for the whole watershed $[18,33]$. The local ecosystem is sensitive to fluctuations or changes in the typical continental climate. The dominant land cover types are grassland and forest, which strongly influence the water quality, quantity, and sediment load $[28,36]$. Despite advances in the understanding of regional climate variation and its interactions with land cover processes, an accurate study of local vegetation dynamics using normalized difference vegetation index (NDVI) and climate-vegetation interaction in China has not been systematically undertaken.

Climatic and human activities can influence land cover status and eco-environment quality [17]. The vegetation in the upper stream of Yellow River is sensitive to temperature and it is an important indicator for monitoring possible climate variation [38]. Serious vegetation degradation, rapid desertification, and wetland degradation have resulted from human disturbance and global warming. The area of desertified land in the upper stream of Yellow River is increasing at an annual rate of $1.83 \%$ [24]. The water flow quantity in Yellow River has experienced a steady decrease since the 1970s [10]. The fluctuations in water flow have affected vegetation distribution and consequently a number of alpine meadows, resulting in the alpine meadows being seriously depredated [5]. Grassland degradation was an important environmental concern over the last several decades in the whole watershed [35]. Although there have been some studies on climate feature in the upper stream of 
Yellow River, few studies have connected climate feature with the monthly and yearly vegetation dynamics. It is important to analyze the vegetation dynamics in relation to the impact of climatic characteristics.

The impacts of climate on regional ecosystem processes can be demonstrated by the response of vegetation to climate feature with the application of remote sensing (RS). RS has the potential to monitor and detect land cover change at a variety of spatial and temporal scales, especially with high temporal resolution satellite data [3, 32]. NDVI has been widely used in biophysical remote sensing studies. The NDVI is calculated by the amount of reflectance in near infrared and red portions of the electromagnetic spectrum and is an efficient indicator for vegetation photosynthesis dynamics [26]. The NDVI has been applied to measure biophysical variables such as leaf area, canopy coverage, land cover characteristics, chlorophyll density, as well as vegetation dynamics $[7,12,16,34]$.

The temporal and spatial resolution of the RS data is an essential issue for many applications. In the last century, time series AVHRR NDVI data with 1 or $8 \mathrm{~km}$ spatial resolution have been widely used to classify land cover patterns at regional or continental scale. However, the coarse spatial resolution of the data has limited many applications [9, 37]. From 2000 onwards, the Moderate Resolution Imaging Spectroradiometer (MODIS) instrument onboard NASA's Terra satellite can scan 36 spectral bands, having a spectral range from the visible to thermal infrared wavelengths. The first seven bands are primarily designed for remote sensing of the land surface with a spatial resolution of $250 \mathrm{~m}$ [25]. The MODIS can provide moderate spatial and high temporal resolution data, which offers a good opportunity to monitor and analyze regional land surface processes. MODIS data have been commonly applied in diverse missions because of its advantages of providing daily data and has offered new possibilities for studies over a large area $[14,21]$. The NDVI information from MODIS $250 \mathrm{~m}$ product has been applied in China already and has shown significant relationship with vegetation properties [22].

The objectives of this paper are to use multi-temporal MODIS data to extract vegetation distribution characteristics and dynamics in the upper stream of Yellow River, emphasizing on the daily NDVI variation of vegetations and its temporal response to climatic variations. The interannual and monthly relationships between the daily NDVI variation and precipitation, the highest temperature and the lowest temperature were analyzed, respectively. The connection of land cover transformation with different climatic indexes is helpful for the prediction of land cover status under conditions of climate variation, which can be useful for regional environmental management.

\section{Methods}

\subsection{Study Area}

The study area is in the upper part of Yellow River Basin and is the connection of Qinghai-Tibet Plateau and Loess Plateau (Fig. 1). This region is the most important waterholding area for the whole Yellow River Basin and nearly $49.2 \%$ of its water flow comes from the region. The typical continental climate in this area is cold, dry, and its yearly

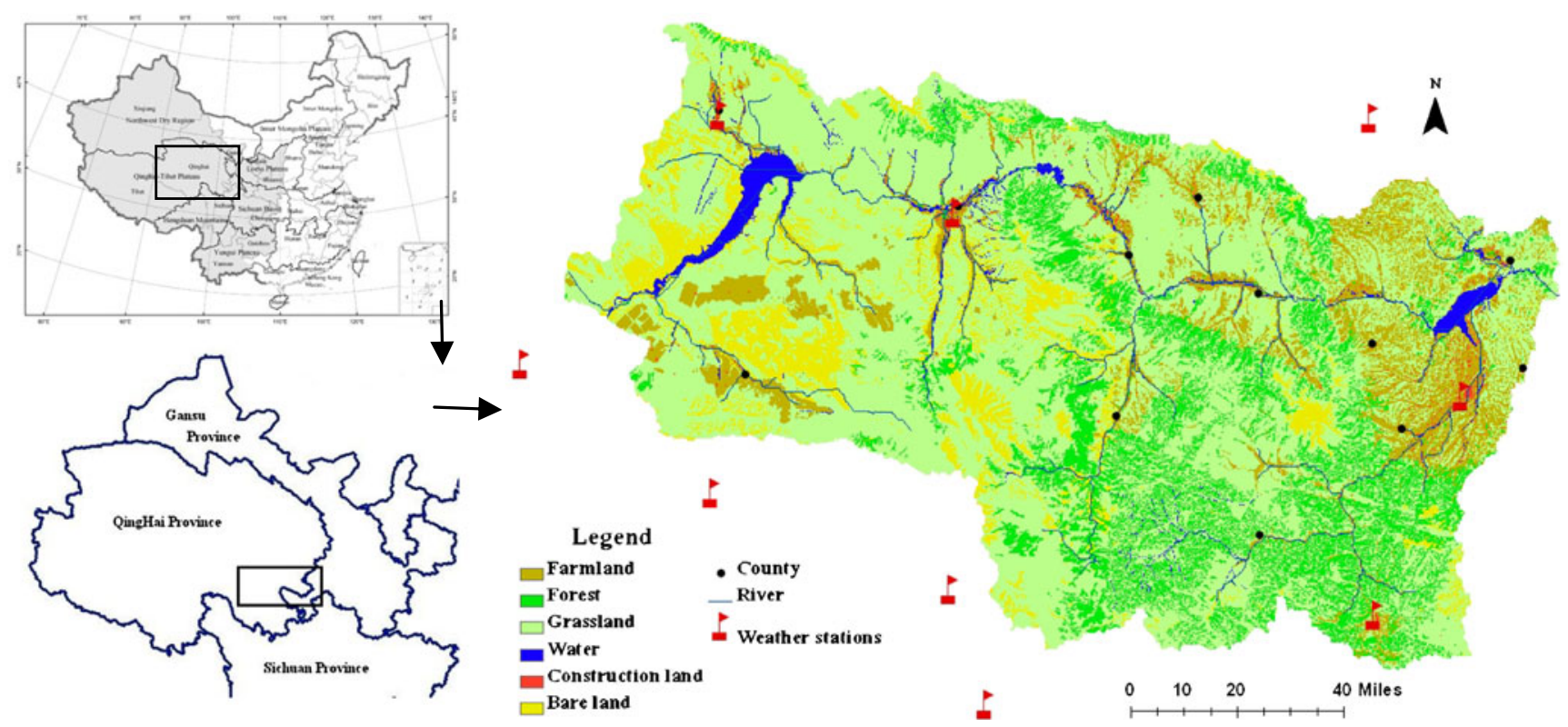

Fig. 1 Location of study area, land cover, and weather stations distribution in the upper stream of Yellow River 
average temperature is $-2.3^{\circ} \mathrm{C}$. Land desertification is one of the main changes in the regional environment and threatens the environmental stability [6]. The vegetation consists of alpine meadow and alpine steppe species, which are typical for the pasturelands in southern Qinghai Plateau. The deciduous forests locate in the mountainous areas and the villages mainly spread near the water. Steppe appears in most part of the watershed and the dominant species are Stipa krylovii, Orinus thoroldii, Stipa breviflora, and Artemisia frigida. Desert steppe occurs in the west of the research area, and the dominant species are $S$. breviflora, Heterocappus altaicus, Poa annua, Carex duriuscula, and Leymus secalinus [29].

\subsection{MODIS Image Processing}

The NDVI data were extracted from the MODIS NDVI product (MOD13Q1), which were obtained from the land processes distributed active archive center, NASA. The NDVI was calculated from the MODIS surface reflectance of the red band (610-680 nm) and near infrared band (780 $890 \mathrm{~nm}$ ), which were corrected with molecular scattering, ozone absorption, and aerosols. This $250-\mathrm{m}$ spatial resolution NDVI dataset has a temporal resolution of 16 days [23]. According to local land cover and climatic characteristics, a 12 series of MODIS NDVI data, starting from February 18 to December 18 in 2000, 2003, and 2006, were ordered from the EOS data gateway website. Data were required from the MODIS tile (h26 v05) for statewide coverage. Then, the NDVI images were mosaicked and geo-referenced to the Universal Transverse Mercator projection system by nearest-neighbor resampling method [27].

\subsection{Regional Climatic Processing}

Precipitation is a direct factor influencing vegetation primary productivity, especially in arid and semi-arid environments, but other climatic indicators, such as solar radiation, temperature, and wind, also have impact on vegetation productivity [19]. In order to analyze the relationship between vegetation biomass and climatic features, the daily precipitation, highest temperature, and lowest temperature were selected to express climatic characteristic. The weather information, monitored at a daily interval, was collected from nine local weather stations in or around the study area (Fig. 1). The altitude of the stations ranged from 1,814 to $3,500 \mathrm{~m}$.

The yearly and monthly average rainfall, highest temperature, and lowest temperature in 2000, 2003, and 2006 were used to explore the correlation with NDVI. Three climatic variables were interpolated by Universal Kriging method with latitude, longitude, and elevation as independent variables. The interpolation includes the local variation as it uses a neighborhood centered on the location being estimated. This method considers the trend component as unvaried, thus the linear estimation is expressed as a linear combination [2, 4]. Elevation was expressed in meter to minimize the validated root mean square interpolation; latitude and longitude were expressed in unit of degree. The spatial variation of the three selected climatic variables was expressed at a grid resolution of $250 \mathrm{~m}$, which was considered to be appropriate in order to represent the variation in the topographically dependent variables and having the same resolution of NDVI data from MODIS [11].

All the correlation results in this paper were performed on $F$ test and the adjusted coefficient of determination $\left(R^{2}\right)$ was used to estimate the goodness of fit. The $p$ is the probability to refuse the regression results.

\section{Results}

\subsection{Vegetation NDVI Characteristic}

The regional land cover characteristics were analyzed with the national land cover database in 2000 from the Data Center for Resources \& Environmental Sciences, CAS (Fig. 1). The dominant land cover type was grassland, which occupied $59.57 \%$ of the whole area. Forest and farmland were accounting for $15.49 \%$ and $12.82 \%$ of the study area, respectively. Most of forest was scattered in mountain area and with latitude higher than $2,800 \mathrm{~m}$. The construction land, water area, and bare land occupied the remaining $12.13 \%$. The grassland and forest together, which were considered as critical part of land cover, covered nearly $75 \%$ of the whole area. As especially these vegetations have strong influence on soil erosion and water-holding capacity, they were selected to study the variation of land cover characteristics in the upper steam of Yellow River.

Thirty-six $250 \mathrm{~m}$ NDVI distribution of the indicated three years $(2000,2003$, and 2006) were generated with monthly MODIS imageries. The regional NDVI distribution on Julian day 241 in 2006 is cited in Fig. 2. There was a trend for NDVI to increase from west to east. Moreover, there was a climbing trend present along the southern plateau boundary and in the central east region. In the area around the reservoir located in the west, especially the west bank, the dominant land cover was bare land and the NDVI value was very low. There was also a large patch of bare land in the southeastern part, close to this reservoir and its NDVI value did not change much during the whole year. In the northeastern part of the study area, the NDVI varied intensively over time. During field investigations, it was found that this area was a farmland and the major crops were wheat and maize. 
Fig. 2 The studied watershed with the NDVI values from MODIS data (Julian day 241 in 2006)

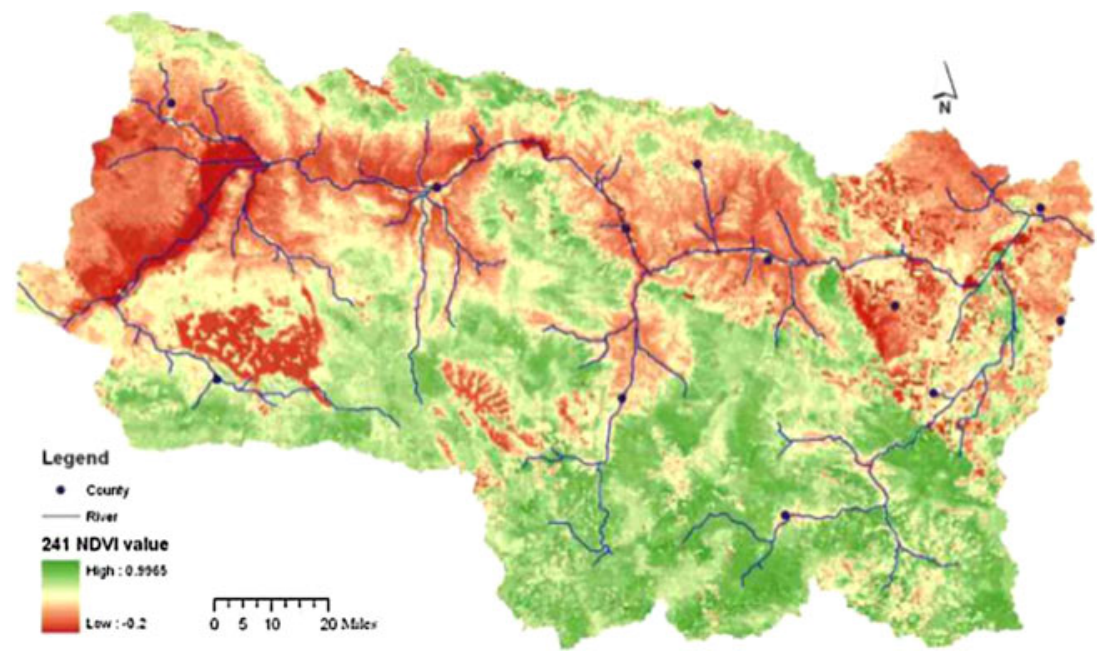

Referring to land cover data, the NDVI values of the two dominant vegetation communities in the selected years were derived and averaged from the MODIS images [30]. The mean NDVI of grassland and forest on 12 days in 2000, 2003, and 2006 was calculated to represent the monthly growth dynamics. The NDVI values for the vegetation of all 36 days were analyzed by SPSS and the results were listed in Table 1. The NDVI values of grassland fluctuated from a minimum (min) of 0.123 on the 49th day in 2000 to a maximum (max) of 0.528 on the 225th day in 2003. The NDVI values of the forest ranged from 0.146 to 0.711 in 3 years. The NDVI value of grassland in 2003 was 0.375 , which was bigger than those in the two other years. The range of forest NDVI in 2003 was the lowest one. Despite different climatic conditions, the minimum NDVI values for grassland and forest were recorded on the 353rd day in 2000 and on the 49th day in 2006, respectively. However, the maximum NDVI seemed to have a different pattern. The maximum NDVI values in 2003 and 2006 were recorded on the 255th day and on the 177 th day in 2000 , respectively. The mean value demonstrated that the NDVI for both grassland and forest increased from 2000 to 2006 .

The monthly NDVI variations of the two vegetation communities are shown in Fig. 3. The NDVI value of the vegetations began to drop from the middle of August. The NDVI values in 2003 and 2006 were overlaid for most of the period. The vegetation did not grow obviously during the first 3 months of 2003 and 2006, but had a higher NDVI in the middle of the year. The NDVI values in spring of 2000 were much lower than that in other 2 years and the maximum value occurred a month earlier than in normal occasions. Comparing to the standard deviations (Table 1), the NDVI values of vegetation distributed in a smaller range from 2000 to 2006.

Time series correlation models of the NDVI variations of grassland and forest in these 3 years were deduced (Table 2). The independent $\mathrm{x}$ in correlation model is the Julian day. All these exponential dynamic models had a strong coefficient of correlation determination $\left(R^{2}\right)$, which ranged from 0.815 to $0.951(p<0.01)$. The higher $R^{2}$ value indicates that the achieved models can objectively describe the daily variation of NDVI value. The regional NDVI value could be calculated and assessed daily by using these models. The NDVI is an important index for environmental simulation and assessment. With simulated NDVI under similar climatic condition, the daily vegetation quality can be quantified effectively, which can indicate regional eco-environmental quality.
Table 1 Statistical analysis of NDVI of grassland and forest in 2000, 2003, and 2006

Min minimum, Max maximum, Std. dev. standard deviation

\begin{tabular}{|c|c|c|c|c|c|c|}
\hline \multirow{2}{*}{$\begin{array}{l}\text { Year } \\
\text { Index }\end{array}$} & \multicolumn{3}{|c|}{ Grassland } & \multicolumn{3}{|l|}{ Forest } \\
\hline & 2000 & 2003 & 2006 & 2000 & 2003 & 2006 \\
\hline Range & 0.356 & 0.375 & 0.313 & 0.566 & 0.439 & 0.566 \\
\hline Min & 0.130 & 0.153 & 0.190 & 0.146 & 0.255 & 0.254 \\
\hline Min day & 49 & 353 & 49 & 49 & 353 & 49 \\
\hline Max & 0.486 & 0.528 & 0.503 & 0.712 & 0.694 & 0.676 \\
\hline Max day & 177 & 225 & 225 & 177 & 225 & 225 \\
\hline Mean & 0.307 & 0.323 & 0.345 & 0.433 & 0.448 & 0.463 \\
\hline Std. dev. & 0.137 & 0.142 & 0.126 & 0.208 & 0.179 & 0.169 \\
\hline
\end{tabular}


Fig. 3 NDVI variation of grassland and forest in the years 2000, 2003, and 2006

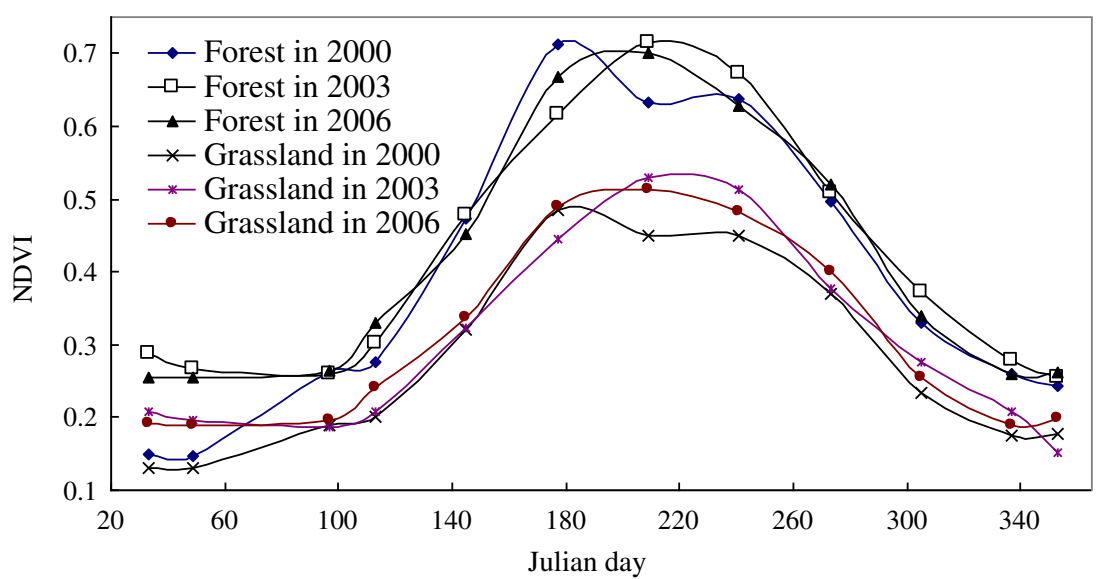

\subsection{Climatic Data Calculation}

Distributions of the interpolated yearly precipitation in the 3 years are mapped in Fig. 4a, which observed a similar spatial trend. The precipitation became less from southeast to northwest. The maximum rainfall occurred in 2006, which was $671.77 \mathrm{~mm}$. The spatial distribution trend of the interpolated annual highest and lowest temperature in the 3 years was the same, but was different from with the precipitation (Fig. 4b, c). It was warmer in the northeastern than in the southwestern part of the study area. Both the annual highest temperature and lowest temperature occurred in 2006 , which were $5528.67^{\circ} \mathrm{C}$ and $856.76^{\circ} \mathrm{C}$, respectively.

Regional annual climatic values in 2000, 2003, and 2006 were averaged based on the interpolated data. The yearly precipitation in 3 years was $301.80,396.04$, and $426.03 \mathrm{~mm}$, respectively. The yearly highest and lowest temperatures are also listed in Table 3. The highest and lowest temperatures both climbed from 2000 to 2006, which might indicate a shift to a warmer climate. The temperature increased much more from 2003 to 2006 than from 2000 to 2003 . The climatic index was also calculated by simple average method from nine weather stations. The directly averaged value was very close to the interpolated value. The biggest difference of annual precipitation was just $19.39 \mathrm{~mm}(6 \%)$. The difference

Table 2 Correlation models of NDVI of grassland and forest in 3 years

\begin{tabular}{lllll}
\hline Year & Land cover & Correlation model & $R^{2}$ & $p$ \\
\hline 2000 & Grassland & $y=0.0813^{*} e^{0.0095 x}$ & 0.951 & $<0.01$ \\
& Forest & $y=0.0969^{*} e^{0.0106 x}$ & 0.949 & $<0.01$ \\
2003 & Grassland & $y=0.1068^{*} e^{0.0079 x}$ & 0.815 & $<0.01$ \\
& Forest & $y=0.1645^{*} e^{0.0071 x}$ & 0.828 & $<0.01$ \\
2006 & Grassland & $y=0.1262^{*} e^{0.0072 x}$ & 0.874 & $<0.01$ \\
& Forest & $y=0.1688^{*} e^{0.0073 x}$ & 0.885 & $<0.01$ \\
\hline
\end{tabular}

Note: When Julian day $(d) \leq 210, x=d$; when $d>210, x=420-d$ in yearly lowest temperature was the most obvious and the relative difference was $12.4 \%$. The averaged yearly highest temperature was much close to the interpolated value and the biggest difference was only $1.5 \%$. Overall, the interpolated results of the three climatic indices were similar to the averaged values. Therefore, in the process of monthly correlation analysis, the data of three indicators were just averaged over the daily monitoring data from nine stations.

\subsection{Yearly Correlation Analysis}

It is hypothesized that significantly positive relationships may appear between climatic variables and NDVI value of vegetation. In order to explore inter-annual correlation between them, the annual mean NDVI in each year was selected to represent the vegetations growth. The precipitation and the highest and lowest temperature were employed to describe climatic features. The correlation between NDVI with three climatic indicators is shown in Table 4 . The NDVI of the grassland and forest was closely interacting with precipitation and the $R^{2}$ values were 0.869 and 0.914 , respectively. When the annual precipitation increased from $301.8 \mathrm{~mm}$ in 2000 to $426.0 \mathrm{~mm}$ in 2006, the NDVI value of grassland climbed from 0.307 to 0.345 . At same time, the NDVI value of forest increased to 0.463 . The analyses proved that more precipitation would definitely lead to higher NDVI value.

The NDVI of vegetations also had a strong linkage with the yearly highest temperature, so higher temperature led to higher NDVI value of vegetation. Although forest had a stronger relationship with NDVI than grassland, the yearly lowest temperature did not have a close correlation with NDVI.

\subsection{Monthly Correlation Analysis}

The correlation analysis between annual climatic index and NDVI showed that the lowest temperature did not have strong relationship with vegetation. In order to examine the 


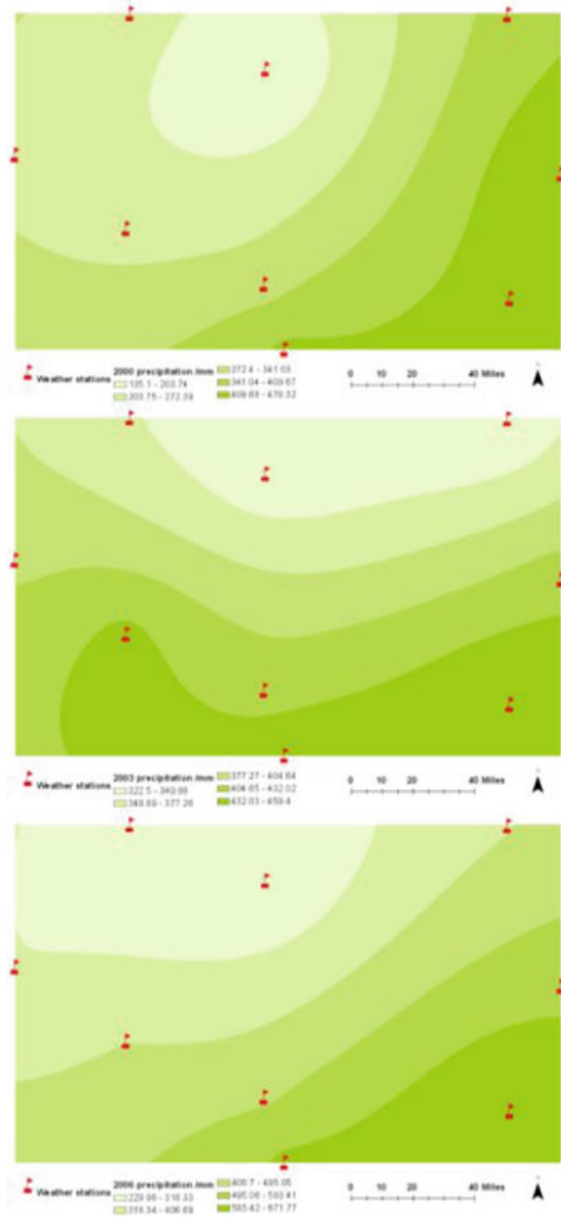

A Precipitation
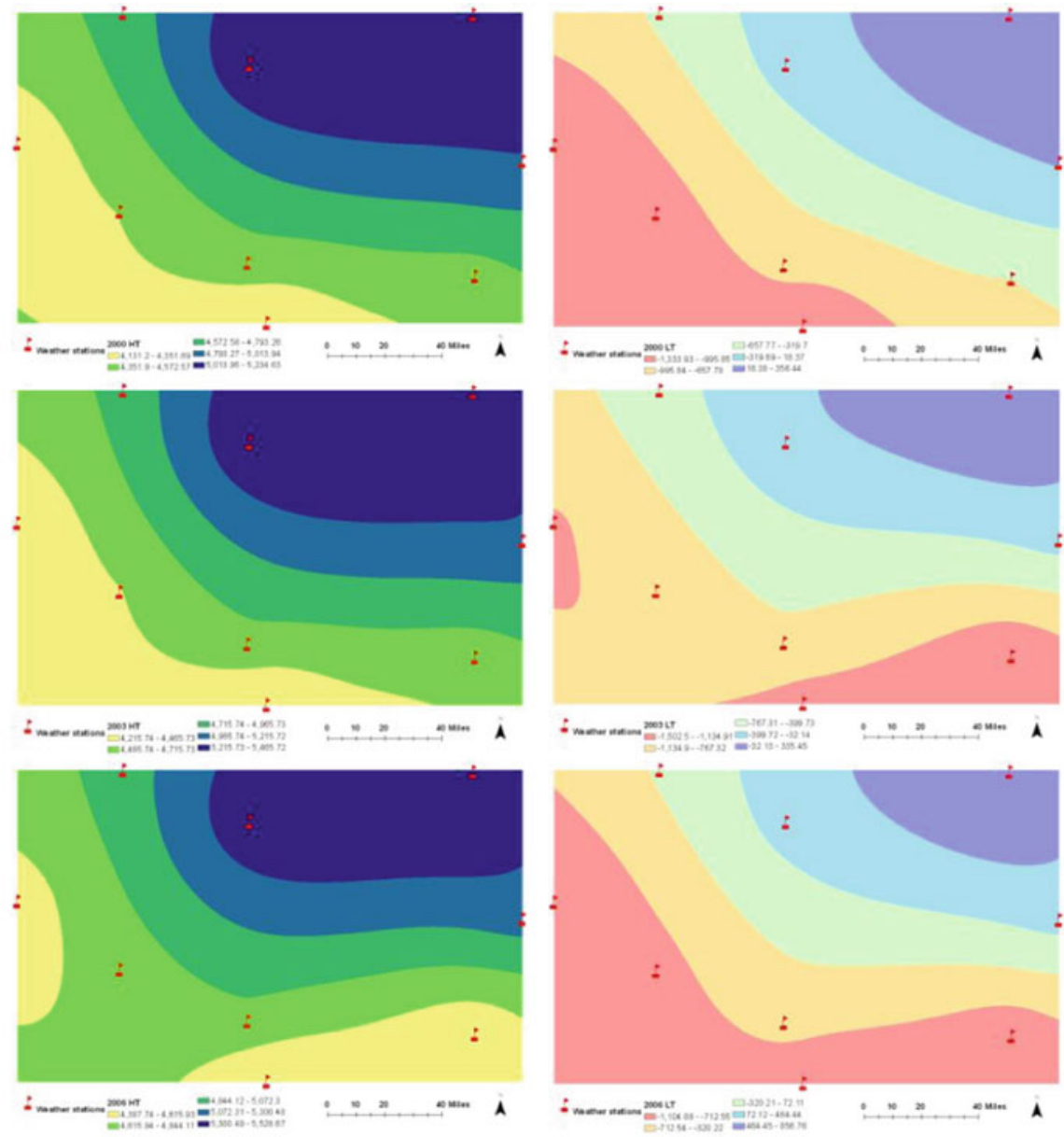

B Highest temperature (HT)

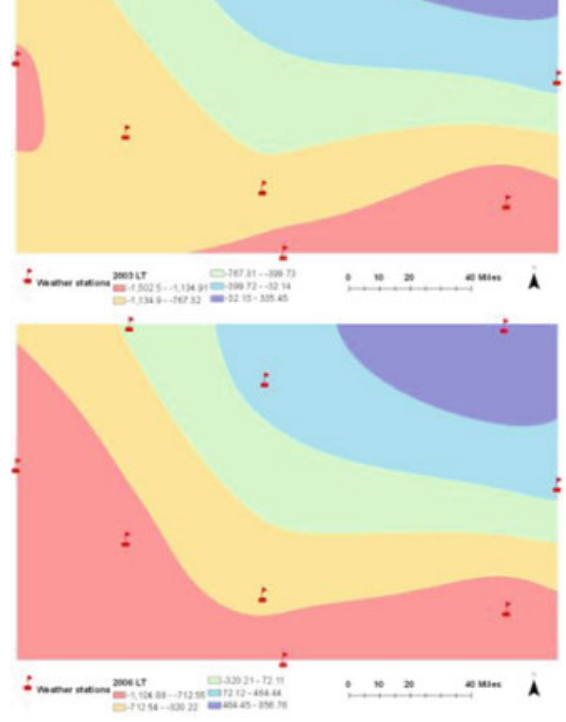

C Lowest temperature (LT)

Fig. 4 The distribution of the annual summed climatic values in 2000, 2003, and 2006

interaction in more detail, the monthly correlations were calculated. The same three climatic variables were correlated with the monthly NDVI of vegetations, and the results are presented in Fig. 5. The $p$ value of all correlation models was less than 0.01 . The NDVI of grassland and forest was exponentially correlated with monthly lowest temperature and the $R^{2}$ values were 0.862 and 0.838 , respectively. The monthly highest temperature was less strongly correlated with NDVI, as the $R^{2}$ values with grassland and forest were 0.823 and 0.816 , respectively.
The NDVI of forest had the lowest interaction with precipitation, but the $R^{2}$ value was high as 0.733 . The widely distributed grassland had a higher $R^{2}$ value with climatic indicators than forest, which meant that grassland was more sensitive to the variations in the weather. The hypothesized positive correlation between the climatic index and NDVI of vegetation has been confirmed.

Figure 5 also demonstrates that the monthly data of climatic indicators are scattered in two zones (left zone and right zone). In the left zone of the two temperature indices,

Table 3 Comparison of climatic index after interpolation with averaged values

\begin{tabular}{|c|c|c|c|c|c|c|c|c|c|}
\hline \multirow{2}{*}{$\begin{array}{l}\text { Index } \\
\text { Year }\end{array}$} & \multicolumn{3}{|c|}{ Yearly precipitation $/ \mathrm{mm}$} & \multicolumn{3}{|c|}{ Yearly highest temperature $/{ }^{\circ} \mathrm{C}$} & \multicolumn{3}{|c|}{ Yearly lowest temperature $/{ }^{\circ} \mathrm{C}$} \\
\hline & 2000 & 2003 & 2006 & 2000 & 2003 & 2006 & 2000 & 2003 & 2006 \\
\hline Averaged & 321.19 & 398.77 & 437.67 & $4,641.81$ & $4,780.56$ & $4,885.69$ & -633.91 & -715.50 & -396.57 \\
\hline Interpolated & 301.80 & 396.04 & 426.03 & $4,698.51$ & $4,851.53$ & $4,942.84$ & -596.19 & -678.35 & -347.40 \\
\hline Difference & 19.39 & 2.72 & 11.64 & 56.70 & 70.98 & 57.15 & 37.72 & 37.15 & 49.17 \\
\hline Error percent & $6.0 \%$ & $0.7 \%$ & $2.7 \%$ & $1.2 \%$ & $1.5 \%$ & $1.2 \%$ & $6.0 \%$ & $5.2 \%$ & $12.4 \%$ \\
\hline
\end{tabular}


Table 4 Correlation models between climatic index and NDVI
NDVI normalized difference vegetation index

\begin{tabular}{llll}
\hline Independent $(X)$ & Correlation equation & $R^{2}$ & $p$ \\
\hline Yearly precipitation & $\mathrm{NDVI}_{\text {Grassland }}=0.0003^{*} X+0.2215$ & 0.869 & $<0.20$ \\
& $\mathrm{NDVI}_{\text {Forest }}=0.0002^{*} X+0.3672$ & 0.914 & $<0.20$ \\
Yearly highest temperature & $\mathrm{NDVI}_{\text {Grassland }}=0.0002^{*} X-0.4094$ & 0.950 & $<0.15$ \\
& $\mathrm{NDVI}_{\text {Forest }}=0.0001^{*} X-0.1172$ & 0.977 & $<0.10$ \\
Yearly lowest temperature & $\mathrm{NDVI}_{\text {Grassland }}=0.0001^{*} X+0.372$ & 0.589 & $<0.40$ \\
& $\mathrm{NDVI}_{\text {Forest }}=0.00006^{*} X+0.4812$ & 0.523 & $<0.40$ \\
\hline
\end{tabular}

the vegetations NDVI just fluctuated a little, but increased rapidly in the right zone with higher temperature. The conjunction point of two zones was the threshold value of the temperature, beyond which vegetation began to grow. The threshold values of the lowest and highest temperature for the two vegetation zones were the same, which were $0^{\circ} \mathrm{C}$ and $13^{\circ} \mathrm{C}$, respectively. Although the NDVI increased in the left zone when relating it to precipitation, beyond the threshold point $(14 \mathrm{~mm})$, the NDVI of both vegetations climbed into a higher step, but remained steady very strangely. The analyses of correlation between monthly climatic variation and NDVI provided a threshold value of precipitation and temperature for inducing the vegetation growth.
Fig. 5 Correlation model between NDVI of grassland and forest with monthly climatic variation [general fitting trend line (broken line), zone fitting trend line (straight line), threshold point (arrow)]
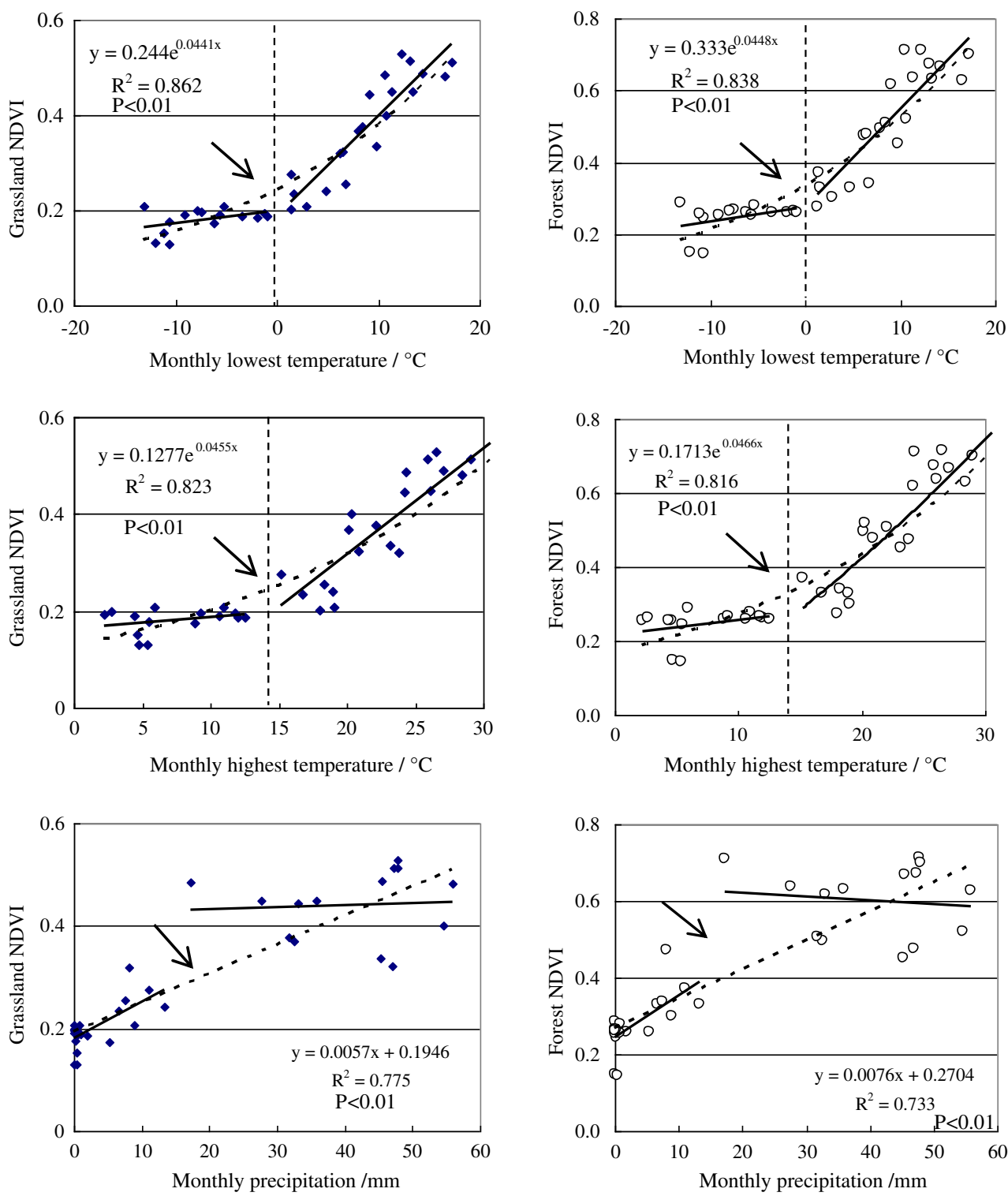


\section{Discussion}

\subsection{Correlation of NDVI and Climatic Indicators}

The inter-annual correlations show that the grassland and forest NDVI could increase by 0.003 and 0.002 , respectively, if there is more $10 \mathrm{~mm}$ rainfall. The highest temperature was less sensitive than the precipitation. The $R^{2}$ values of the three climatic indices with monthly NDVI are higher than 0.733 , which demonstrates strong interactions between them.

The increased NDVI of vegetation can improve local ecosystem stability, which can reduce soil erosion, resulting in better water quality [1]. The NDVI can be predicted using climatic parameters, which can improve the efficiency of environmental management. The lowest temperature, not precipitation, is most strongly correlated with NDVI, as not same with previous studies [13]. The correlations between climatic indicators and NDVI have been observed for a long period, which demonstrates complex relationships between vegetation growth and climate variables [8]. In a similar arid region, Weiss et al. [31] also proved that precipitation was not principally correlated with NDVI change. Climate change across Qinghai-Tibet Plateau has been modulated on decadal century timescales. The scientists have predicted that the temperature in Qinghai-Tibet Plateau will increase with $0.20^{\circ} \mathrm{C}$ every century [15]. The regional severe drought periods have happened in recent decades. Consequently, the correlation model between climatic index and NDVI can be used to simulate regional NDVI variations.

\subsection{Application in Regional Environmental Management}

Vegetation cover had significant interactions with diffuse pollution formation and transportation [20]. In this paper, the temporal interactions between vegetation and climatic indicators were identified. The climatic data can be monitored every hour, which are a reliable data for analyses of regional environmental processes. With these correlations, the vegetation status can be simulated effectively at a higher resolution of temporal scale. With China's Westward Development Plan, the economic development will impose more pressure on local environmental quality conservation. The water resource in this area will attract more attention, as eight dams have been constructed in this area, which will have a direct influence on the regional landscape pattern. In future, even more dams are planned to be constructed in the upper stream of Yellow River [20]. The findings will be applicable and fundamental in the process of preserving land cover and minimizing negative environmental impact.

\section{Conclusion}

By applying NDVI and climatic data from 2000 through 2006, the time series of grassland and forest communities NDVI correlation equations were developed for the upper stream of the Yellow River. The results confirm the utility of NDVI as an index to express vegetation variability at a watershed scale with continental climate at high latitude and with little precipitation. The findings also added knowledge of complex understanding about climate and vegetation. The inter-annual and monthly relationships between grassland and forest NDVI with climatic variables have been estimated. The correlation coefficients confirmed the strong relationships between NDVI and climate characteristics. The strongest inter-annual correlation between climatic variables and NDVI were precipitation and the highest temperature, which were different from the monthly correlation pattern. Overall, the results indicated that the monthly lowest temperature had the most pronounced impact on land cover change. The monthly highest temperature and precipitation also remarkably affected NDVI value. With the monthly correlation analyses, the threshold values of three climatic indictors can also be calculated.

As stated in this study, correlations between NDVI with climatic variables have implications for research on climate and vegetation in the upper stream of the Yellow River. The daily variation of the regional vegetation can be predicted under similar climatic conditions. The response of NDVI of regional vegetation to climate feature can be assessed much more accurately by climatic data, which is critical for vegetation assessments. The other eco-environmental factors can be calculated further from vegetation quality simulation and prediction.

Acknowledgments The authors would like to thank Dong Dehong and Zhang Fugui from the Forestry Academic of Qinghai Province. The anonymous reviewers and advisory editor also provided helpful advice. This research benefited from the financial support of the National Natural Science Foundation of China (grant no. 40930740, 41001317), New Teacher Fund for Doctor Station, Ministry of Education (20100003120030).

Open Access This article is distributed under the terms of the Creative Commons Attribution Noncommercial License which permits any noncommercial use, distribution, and reproduction in any medium, provided the original author(s) and source are credited.

\section{References}

1. Arsenault, E., \& Bonn, F. (2005). Evaluation of soil erosion protective cover by crop residues using vegetation indices and spectral mixture analysis of multispectral and hyperspectral data. Catena, 62(2-3), 157-172. 
2. Belda, F., \& Melia, J. (2000). Relationships between climatic parameters and forest vegetation: Application to burned area in Alicante (Spain). Forest Ecology and Management, 135(1-3), 195-204.

3. Carlson, T. N., \& Arthur, S. T. (2000). The impact of land useland cover changes due to urbanization on surface microclimate and hydrology: a satellite perspective. Global and Planetary Change, 25(1-2), 49-65.

4. Carrera-Hernandez, J. J., \& Gaskin, S. J. (2007). Spatio temporal analysis of daily precipitation and temperature in the Basin of Mexico. Journal of Hydrology, 336(3-4), 231-249.

5. Chen, J. S., He, D. W., \& Cui, S. B. (2003). The response of river water quality and quantity to the development of irrigated agriculture in the last 4 decades in the Yellow River Basin, China. Water Resources Research, 39(3), 1047.

6. Feng, J. M., Wang, T., Qi, S. Z., \& Xie, C. W. (2005). Land degradation in the source region of the Yellow River, northeast Qinghai-Xizang Plateau: Classification and evaluation. Environmental Geology, 47(4), 459-466.

7. Fensholt, R., Sandholt, I., \& Rasmussen, M. S. (2004). Evaluation of MODIS LAI, fAPAR and the relation between fAPAR and NDVI in a semi-arid environment using in situ measurements. Remote Sensing of Environment, 91(3-4), 490507.

8. Fritts, H. C. (1974). Relationships of ring widths in arid-site conifers to variations in monthly temperature and precipitation. Ecological Monographs, 44, 411-440.

9. Hansen, M. C., DeFries, R., Townshend, S., Sohlberg, R., Dimiceli, C., \& Carroll, M. (2002). Towards an operational MODIS continuous field of percent tree cover algorithm: Examples using AVHRR and MODIS data. Remote Sensing of Environment, 83(1-2), 303-319.

10. Yi, H., Jialiang, C., He, Y., \& Mantang, C. (2009). Correlation of precipitation to temperature variation in the Huanghe River (Yellow River) basin during 1957-2006. Journal of Hydrology, 372(1-4), 1-8.

11. Jeffrey, S. J., Carter, J. O., Moodie, K. B., \& Beswick, A. R. (2001). Using spatial interpolation to construct a comprehensive archive of Australian climate data. Environmental Modelling and Software, 16(4), 309-330.

12. La Puma, I. P., Philippi, T. E., \& Oberbauer, S. F. (2007). Relating NDVI to ecosystem $\mathrm{CO} 2$ exchange patterns in response to season length and soil warming manipulations in arctic Alaska. Remote Sensing of Environment, 109(2), 225-236.

13. Lin, G., Phillips, S. L., \& Ehleringer, J. R. (1996). Monsoonal precipitation responses of shrubs in a cold desert community on the Colorado Plateau. Oecologia, 106(1), 8-17.

14. Loboda, T. V., \& Csiszar, I. A. (2007). Reconstruction of fire spread within wildland fire events in Northern Eurasia from the MODIS active fire product. Global and Planetary Change, 56(34), 258-273.

15. Long, H., Mao, L. Q., Che, Z. X., \& Yang, G. W. (2006). Impact on water resources in Yellow River with climatic change. Journal of Water Resources and Water Engineering, 17 (4), 74-77.

16. Lu, H., Raupach, M. R., McVicar, T. R., \& Barrett, D. J. (2003). Decomposition of vegetation cover into woody and herbaceous components using AVHRR NDVI time series. Remote Sensing of Environment, 86(1), 1-18.

17. McAlpine, C. A., Syktus, J., Deo, R. C., Lawrence, P. J., McGowan, H. A., Watterson, I. G., et al. (2007). Modeling the impact of historical land cover change on Australia's regional climate. Geophysical Research Letters, 34(22), L22711.
18. Neal, C., Reynolds, B., Neal, M., Hughes, S., Wickham, H., Hill, L., et al. (2003). Soluble reactive phosphorus levels in rainfall, cloud water, through fall, stem flow, soil waters, stream waters and ground waters for the Upper River Severn area, Plynlimon, mid Wales. The Science of the Total Environment, 314(10), 99120.

19. Okin, G. S., Murray, B., \& Schlesinger, W. H. (2001). Degradation of sandy arid shrubland environments: Observations, process modeling, and management implications. Journal of Arid Environments, 47(2), 123-144.

20. Ouyang, Wei, Wang, Xuelei, Hao, Fanghua, \& Srinivasan, R. (2009). Temporal-spatial dynamics of vegetation variation on nonpoint source nutrient pollution. Ecological Modeling, 220(20), $2702-2713$.

21. Pflugmacher, D., Krankina, O. N., \& Cohen, W. B. (2007). Satellite-based peatland mapping: Potential of the MODIS sensor. Global and Planetary Change, 56(3-4), 248-257.

22. Piao, S. L., Fang, J. Y., \& He, J. S. (2006). Variations in vegetation net primary production in the Qinghai-Xizang Plateau, China, from 1982 to 1999. Climatic Change, 74(13), 253-267.

23. Olofsson, P., Eklundh, L., Lagergren, F., et al. (2007). Estimating net primary production for Scandinavian forests using data from Terra/MODIS. Advances in Space Research, 39(1), 125-130.

24. Qian, W. H., Xu, T., \& Quan, L. S. (2004). Regional characteristics of dust storms in China. Atmospheric Environment, 38(29), 4895-4907.

25. Running, S. W., Justice, C. O., Salomonson, V., Hall, D., Barker, J., Kaufmann, Y. J., et al. (1994). Terrestrial remote sensing science and algorithms planned for EOS/MODIS. International Journal of Remote Sensing, 15(17), 3587-3620.

26. Seaquist, J. W., Olsson, L., \& Ardö, J. (2003). A remote sensingbased primary production model for grassland biomes. Ecological Modelling, 169(1), 131-155.

27. Stefanov, W. L., \& Netzband, M. (2005). Assessment of ASTER land cover and MODIS NDVI data at multiple scales for ecological characterization of an arid urban center. Remote Sensing of Environment, 99(1-2), 31-43.

28. Wang, G. X., Cheng, G. D., Shen, Y. P., \& Qian, J. (2003). Influence of land cover changes on the physical and chemical properties of alpine meadow soil. Chinese Science Bulletin, 48(2), 118-124.

29. Wang, X. D., Li, M. H., Liu, S. Z., \& Liu, G. C. (2006). Fractal characteristics of soils under different land-use patterns in the arid and semiarid regions of the Tibetan Plateau, China. Geoderma, 134(1-2), 56-61.

30. Weiss, J. L., Gutzler, D. S., Coonrod, J. E. A., \& Dahm, C. N. (2004). Seasonal and inter-annual relationships between vegetation and climate in central New Mexico, USA. Journal of Arid Environments, 57(4), 507-534.

31. Weiss, J. L., Gutzler, D. S., Gutzler, D. S., Coonrod, J. E. A., \& Dahm, C. N. (2004). Long-term vegetation monitoring with NDVI in a diverse semiarid setting, central New Mexico, USA. Journal of Arid Environments, 58(2), 249-272.

32. Wittenberg, L., Malkinson, D., Beeri, O., Halutzy, A., \& Tesler, N. (2007). Spatial and temporal patterns of vegetation recovery following sequences of forest fires in a Mediterranean landscape. Mt. Carmel Israel. Catena, 71(1), 76-83.

33. Xu, J. X., \& Yan, Y. X. (2005). Scale effects on specific sediment yield in the Yellow River basin and geomorphological explanations. Journal of Hydrology, 307(1-4), 219-232.

34. Xu, X. K., Levy, J. K., Lin, Z. H., \& Hong, C. (2006). An investigation of sand-dust storm events and land surface characteristics in China using NOAA NDVI data. Global and Planetary Change, 52(1-4), 182-196. 
35. Yang, J. P., Ding, Y. J., \& Chen, R. S. (2006). Spatial and temporal of variations of alpine vegetation cover in the source regions of the Yangtze and Yellow Rivers of the Tibetan Plateau from 1982 to 2001. Environmental Geology, 50(3), 313322.

36. Zeng, Y. N., Feng, Z. D., \& Cao, G. C. (2003). Land cover change and its environmental impact in the Upper reaches of the Yellow River, Northeast Qinghai-Tibetan Plateau. Mountain Research and Development, 23(4), 353-361.
37. Zhan, X., Sohlberg, R. A., Townshend, J. R. G., DiMiceli, C., Carroll, M. L., Eastman, J. C., et al. (2002). Detection of land cover changes using MODIS $250 \mathrm{~m}$ data. Remote Sensing of Environment, 83(1-2), 336-350.

38. Zhou, D. W., Fan, G. Z., Huang, R. H., Fang, Z. F., Liu, Y. Q., \& $\mathrm{Li}, \mathrm{H}$. Q. (2007). Interannual variability of the normalized difference vegetation index on the Tibetan plateau and its relationship with climate change. Advance in Atmospheric Science, 24(3), 474-484. 